\title{
Convergence of logistics planning and execution in outsourcing
}

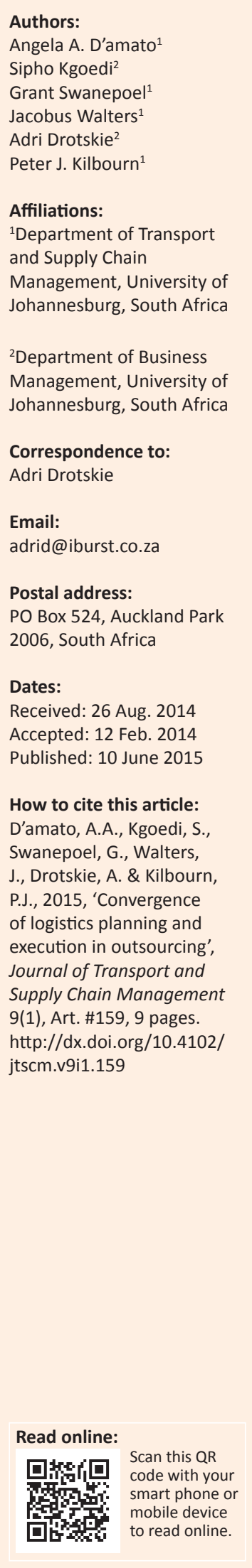

Background: Logistics service providers (LSPs) are becoming increasingly involved in their clients' businesses. Beyond just providing vehicles and buildings, LSPs are now becoming involved with knowledge-related work that is connected to the traditional services provided.

Objectives: To investigate the likelihood and potential value of LSPs extending their range of services to their clients by means of a convergence of planning and execution activities.

Method: In the research through a literature review and empirical study presented here, attention is given to the practical impact that convergence planning and execution functions have on business success, as well as how selected clients of an LSP (referred to in this article as logistics company A or LCA) perceive the impact of increased integration of LCA within its businesses. The results should assist LCA and other LSPs considering the same objective to ascertain the opportunities and key requirements associated with a strategy to converge planning and execution activities for their clients.

Results: The study found that the vast majority of respondents see value in the convergence of planning and execution activities.

Conclusion: Such convergence will be challenging, owing to the importance of the planning function for clients, as well as key collaborative and measurement requirements that will have to be put in place for successful business integration.

\section{Introduction}

Logistics outsourcing is a viable business strategy, because turning non-core functions over to external suppliers enables companies to leverage their resources, spread risks, and concentrate on issues critical to survival and future growth. One way of extending a logistics organisation beyond its boundaries is through the use of a third-party logistics service provider (LSP) or contract logistics services. In an international study Langley and Capgemini Consulting (2011) found that shippers spend on average $12 \%$ of their total revenue on logistics, and of this figure $42 \%$ goes towards outsourced logistics activities. It is becoming common to see LSPs take over an entire supply chain function on behalf of their clients. For the purposes of this study an LSP is broadly defined as 'an external supplier that performs all or part of a company's logistics functions', as per Langley et al. (2009:119).

Traditionally outsourcing of the logistics function has mainly involved the transportation and warehousing of goods. However, critical inputs to successful execution of the outsourced function, such as forecasting, planning and performance measurement, are controlled by the clients and are not openly shared with the LSP. This has often led to the misalignment of execution of operations between the client and the service provider. The LSP ends up duplicating the same functions as the client - for example, both the client and the LSP perform planning functions.

This research was conducted in order to obtain a better understanding of the benefits, risks, costs and value of the changing role of LSPs, shifting focus from a company providing transport and warehousing services only to one that utilises information to conduct planning and execution for its clients. For this purpose logistics functions have been categorised into two groups, namely planning and execution. The planning group represents all the planning activities (outbound and inbound), whilst the execution group refers to other key logistics activities where the emphasis is on performance of an activity rather than the planning thereof. Table 1 shows the grouping of activities.

Note: This study was based on the following Master's Degree study: D’Amato, A.A., Kgoedi, S. \& Swanepoel, G., 2013, Convergence of logistics planning, execution and measurement on outsourcing. Minor dissertation based on a multidisciplinary research project, submitted in partial fulfilment of the requirement for the degree Magister Commercii, University of Johannesburg.

Copyright: @ 2015. The Authors. Licensee: AOSIS OpenJournals. This work is licensed under the Creative Commons Attribution License. 
TABLE 1: Categorisation of logistics functions.

\begin{tabular}{ll}
\hline Planning functions & Execution functions \\
\hline Outbound planning & Outbound transportation \\
Inbound planning & Inbound transportation \\
& Inventory management/control \\
& Warehouse management \\
& Supplier payment management \\
& Order management \\
& Reverse logistics \\
& Systems and technology \\
& Customer payment management \\
\hline
\end{tabular}

Source: Adjusted from D'Amato, Kgoedi and Swanepoel (2013:125)

The primary objective of this research study is to understand the impact of the convergence of logistics planning and execution on business partners in an outsourcing relationship. The study was conducted on behalf of an LSP which was investigating opportunities for expanding service offerings to clients.

\section{Literature review}

The literature review supporting this article focused on logistics outsourcing, planning, execution and the changing role of the LSP, including cultural factors, strategic influences, relationship influences, performance management and the ultimate convergence of these aspects.

In a study conducted by Cranfield University (2010) it was found that a supply chain's impact on overall business performance has become a focus area in terms of costs and value creation (low cost or differentiation competitive strategy). It is evident that in the majority of industries, supply chains - as opposed to organisations - compete for a distinct competitive advantage (Wilding et al. 2010; Zigmund \& Babin 2007).

Identifying inefficiencies in business units such as transport and distribution centres assists in driving continuous improvement and the selected competitive strategy. Tan (2000) indicates that the goal of focusing on continuous improvement is achievement of a distinct competitive advantage in the retail and supply chain environment as well as healthy financial results. Organisations therefore strive to streamline in-house processes and outsource functions that LSPs can perform cost-effectively.

Organisations often choose to outsource logistics functions due to the fact that their own core competency is not logistics. An important factor in deciding to outsource is 'the interest in reducing asset investment to improve asset productivity' (Langley et al. 2009:606). Further benefits are stated by Knemeyer and Murphy (2005) to be customer retention, customer referrals, the ability to recover from unexpected operational disruptions, and operational performance improvements.

Because logistics planning is normally deemed to be an in-house function, organisations often identify it as a critical internal function and wish to retain control over it.
Organisations consider LSPs to be experts only in logistics and supply chain management, and perceive them to be unfamiliar with the core business activities of their client organisations.

There are, however, advantages to involving LSPs in the logistics planning function of an organisation. Long-term partnerships can be created whereby communication, risks and rewards are openly shared between supply chain partners. Organisations that include LSPs in logistics planning capitalise on opportunities for creating sustainable competitive advantages which can improve organisational performance. Fabbe-Costes, Jahre and Roussat (2009) explain that the reason LSPs assist in improving performance of a client's supply chain is due to their ability to collaborate vertically with supply chain partners and horizontally with other LSPs. In addition, LSPs are experts in logistics and supply chain management and are able to assist in supply chain integration.

Due to increasing demands on organisations to remain competitive, the use of outsourcing is likely to increase in the future as LSPs provide improved efficiencies through service integration and incorporation of information technology (Rahman 2011). Because organisations operate in a competitive environment they have adopted a strategic viewpoint to outsourcing, whilst LSPs have begun to focus on a strategic outlook for service differentiation and innovation (Large, Kramer \& Hartmann 2011). Fabbe-Costes et al. (2009) state that organisations not only outsource traditional supply chain functions but have also opted to outsource logistics management functions which include planning functions.

There are two categories of logistics outsourcing which form the basis of this research study, namely, planning activities and execution activities. If the planning and execution functions are outsourced to two different LSPs, the client must act as an integrator between these two organisations. This may result in negative consequences, namely duplicated planning by both LSPs. Because of this the overall utilisation of LSPs has increased and the relationship between the client organisation and the LSP has evolved (Bask 2001) and increased in scope and complexity (Lukassen \& Wallenburg 2010).

In order for client organisations to take full advantage of LSPs, mutually beneficial projects must be created which invite collaboration between supply chain partners. A distinct competitive advantage for supply chain partners can be created by maintaining a constant watch for future challenges and opportunities, and construction of collaborative plans to exploit these opportunities.

The Council of Supply Chain Management Professionals (CSCMP) states that 'logistics management is an integrating function, which coordinates and optimizes all logistics activities, as well as integrates logistics activities with other functions including marketing, sales, manufacturing, finance, and information technology' (CSCMP 2012). Therefore, 
in converging planning and execution and formalising relationships between supply chain partners, organisations can assist in further achievement of the integration ideal that is central to the objective of logistics management.

\section{Research method and design Research approach}

The research presented in this article was conducted at logistics company A (LCA), a South African multifaceted LSP with divisions focusing on transport, warehousing, international logistics and supply chain management. The research methodology is of a quantitative nature, allowing for an objective and detached viewpoint (Creswell 1994). A deductive process was utilised whereby the findings of the survey will be generalised to the population of the study.

\section{Participants}

The study involved no sampling. A census approach was followed because all of the members of the population of this study were approached with a request to participate in the survey. The research population consisted of organisations selected on the basis of the following criteria: the company had to be a client of LCA; the client's company had to perform logistics functions; and the potential had to exist to outsource the clients' logistics functions to LCA. The population for the survey was identified by LCA and comprised of all its client companies that met the abovementioned criteria. These organisations were from various industries but mostly represented the fast-moving consumer goods (FMCG) and manufacturing industries. The population comprised 76 companies, of which 38 responded to a request to complete a questionnaire, as depicted in Table 2.

\section{Measuring instruments or methods of data gathering}

Electronic or online surveys were utilised for this research study, due to the fact that the clients of LCA are geographically dispersed. Benefits of this method of data collecting were that the respondents were able to fill out the survey anonymously, it allowed the researchers to have realtime control of the number and type of responses, and it was deemed to be less biased than a paper-based survey as all of the surveys were administered in the same way.

\section{Procedure}

The data were obtained in the form of structured electronic, online questionnaire surveys. SurveyMonkey, a webbased tool, was used to administer the survey and analyse

TABLE 2: Overall response rate of survey.

\begin{tabular}{lccc}
\hline Companies & \multicolumn{3}{c}{ Companies } \\
\cline { 2 - 4 } & Sent survey & $\begin{array}{c}\text { Returned } \\
\text { survey }\end{array}$ & $\begin{array}{c}\text { Returned survey } \\
\text { fully completed }\end{array}$ \\
\hline Number & 76 & 38 & 31 \\
Percentage & 100 & 50 & 41 \\
\hline
\end{tabular}

Source: Adjusted from D’Amato, Kgoedi and Swanepoel (2013:91) the survey results. The questionnaire consisted of sets of questions, namely contextual, outsourcing, relational and general questions related to planning and execution convergence.

\section{Contextual questions}

The first set of questions attempts to determine the unique characteristics of the respondents. Contextual questions provide a 'place holder' for the questions that follow, allowing the researchers to better understand why a certain response may have been provided. These questions ensure that the respondent matches the target population identified for the research, and assist the researchers in determining validity of the results based on the type of respondent who answered the questions. These questions were included to ensure that the type of respondents completing the survey were knowledgeable enough to accurately respond to the questions. For example, a particular question asks the respondents to specify their main job role, providing an indication as to the skill or level of education of the respondent, and hence their ability to have an informed opinion. A secondary reason why these types of questions were asked is that they can be used to justify or explain why certain responses may have been given later in the survey. For example, another question asks what industry the respondent is involved in. This could potentially provide insight into the respondent's answers later in the survey. The respondents all had experience in this area as they currently outsource logistics activities to the LSP.

\section{Outsourcing questions}

These types of questions have been included to obtain a general sense of the types of functions that are outsourced as a whole and within the supply chain divisions of the companies surveyed. These questions set the scene and include questions that are related to logistics planning and execution. The purpose of asking questions on general outsourcing practices is to understand the general attitudes of the organisations towards outsourcing. Typical questions that were included in this section include what business functions are considered to be core competencies by the respondents as well as which functions are outsourced. The researchers ensured that the answers that could be provided would relate in some way to whether the business function is related to planning or execution.

\section{Relational questions}

These aimed to establish the general perceptions of the client companies surveyed towards their outsourced partner. These questions were included to analyse the degree to which planning and execution is managed and communicated within the company and between the company and the LSP. It was deemed to be important to understand relational issues because the concept of convergence of different functions centres on an organisation being able to coordinate these functions, and this relates closely to communication, measurement and alignment of strategy between supply chain partners. Although the idea of convergence of planning 
and execution is, in the case of this study, related to one company providing both functions, it is important for one to understand the current linkages between an organisation that may be carrying out the planning function and another that is completing the execution function.

\section{General questions related to planning and execution convergence}

This section of the survey focused on core ideas related to the convergence of planning and execution. These questions were intentionally mostly open-ended in order to gain insight into the types of initiatives and methodologies that companies are currently using related to planning and execution convergence. Specifically, the researchers wanted to determine the value created by the convergence of planning and execution activities with an LSP.

Prior to commencement of the survey pilot studies were carried out. The pre-test questionnaires were sent to individuals and feedback on any concerns experienced with the questionnaire was requested. Results of the pilot studies were incorporated into the survey and amendments were made prior to commencement of the formal survey. Piloting assists in ensuring that all aspects of the research study are covered and that the open-ended questions address areas of uncertainty. If the respondent found an area of uncertainty and he or she wished to query it, the researchers' details were supplied at the commencement of the survey to assist with clarification of survey question or questions. Codes were used to more easily identify a specific respondent whilst maintaining their anonymity.

In terms of response legitimacy and data validity, piloting and verification of results was conducted to reduce biases and increase accuracy of the findings. The surveys attempted to identify broad patterns and generalisations in the area of study. The survey remained open for 16 days.

\section{Statistical analysis and/or treatment of the data}

For the purposes of this research analysis data sets were downloaded and charts created to allow for analysis and linking back to meeting the research objective.

\section{Data validity}

Data validity was ensured by using two methods:

- A sample of data from the 16th Annual Third Party Logistics Study (Langley \& Capgemini Consulting 2011) was chosen for comparison with one of the study's questions pertaining to the logistics functions that were outsourced. This was done to ensure that the activities listed were relevant. The 16th Annual Third Party Logistics Study is one of more recent surveys on the subject, and has been used worldwide as the best practice knowledge for outsourcing in logistics.

- To determine whether the data collected were relevant the researchers attempted to link the type of outsourced logistics functions that LSPs currently provide (as identified in the 16th Annual Third Party Logistics Study) to the logistics functions currently outsourced by the survey respondent companies.

Items that could not be matched were removed from the survey. A comparison between the different rankings was then created by calculating the proximity of the ranks (correlations) to each other for the respective categories. From this comparison it was concluded that there was a general close correlation between rankings of elements used within the 16th Annual Third Party Logistics Study and the rankings resulting from this study.

\section{Results and discussion}

The researchers identified three important categories of factors influencing the client's perspective of LSP services and the potential value of the convergence of planning and execution activities, namely contextual and relational factors and strategic alignment. Contextual factors refer to the surrounding attitudes and perceptions of respondents working for the client organisations. Relational issues include what service is offered to which client, as well as how it is structured and measured. Strategic alignment includes a long-term view of an LSP/client relationship and the alignment of strategies between two (or more) organisations, as well as actions the organisations are taking to achieve a long-term goal.

The findings of the study with regard to these three factors are briefly discussed, because it provides a profile of individual respondents and their organisations and contextualises findings.

This section will also provide a discussion of the study's findings on outsourcing practices of respondent companies and respondents' views of potential value to be gained from convergence of planning and execution services by a single LSP supplier.

\section{Contextual factors}

The most important contextual factors are related to the respondents' work role and function and the geographical and industry view. The majority of respondents hold senior management positions in their organisations, with 52\% in general supply chain management and $24 \%$ in general management. It can thus be concluded that a significant percentage of the respondents are decision makers within their organisations and should have a well-grounded view of their organisation's strategic direction.

As depicted in Figure 1, the majority of respondents (58\%) reported that they provide services in the FMCG environment. The manufacturing industry is also well represented at $28.9 \%$. The oil, gas and industrial sectors represent the rest (13\%). The FMCG industry is known as a fairly dynamic environment as it is highly customer-centric and is usually at the forefront of innovation and adaptive processes for client convenience. 


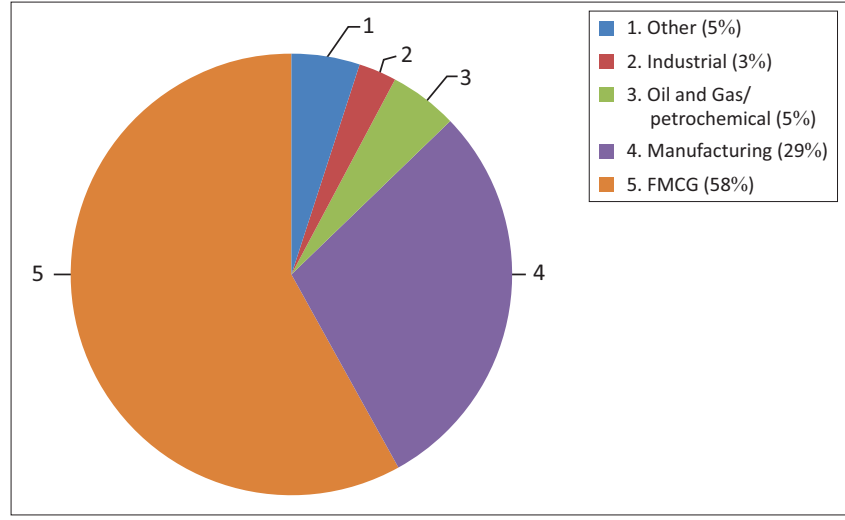

Source: Adjusted from D'Amato, Kgoedi and Swanepoel (2013:100)

FIGURE 1: Primary industry of respondent company.

The geographical context and size of the organisation could also have played a role in determining the view of respondents. Most responding companies (76\%) operate mainly in South Africa and most were also large organisations, illustrated by the fact that $47 \%$ had more than 2000 employees and $40 \%$ reported revenue of more than $\mathrm{R} 5$ billion per annum.

The impact of having such large companies responding to the survey is threefold:

- Bigger companies are more influential and would potentially be in a better position to initiate larger projects related to logistics outsourcing. Such projects include logistics integration centres or large planning competencies.

- Current or potential spend on outsourcing is large and could be quite complex, especially if the subsidiaries and/or outlets are geographically dispersed.

- The inherent competitiveness of large organisations means that they would want to save costs, and if benefits could be identified through converging planning and execution they might consider such initiatives.

The average size of the respondent company has further implications for LSPs. As mentioned earlier, an international survey showed that a relatively large portion (42\%) of total supply chain costs of shippers is allocated to LSPs. If one assumes that this norm also applies to the South African environment, then it means that LSPs have the opportunity to capture the remaining portion of the logistics spend of their clients. This was found to be approximately $6.9 \%$ of the client organisations' revenue.

In this survey the researchers found that $40 \%$ of the respondents (all clients of LCA) have revenue of over R5 billion per annum. Therefore the estimated monetary value of the additional business that LCA could potentially acquire from taking over all of the logistics functions of just one of these clients is R345 million (6.9\% x R5 billion).

\section{Relational factors}

The literature review conducted in this study identified relationship management as the key to success of future

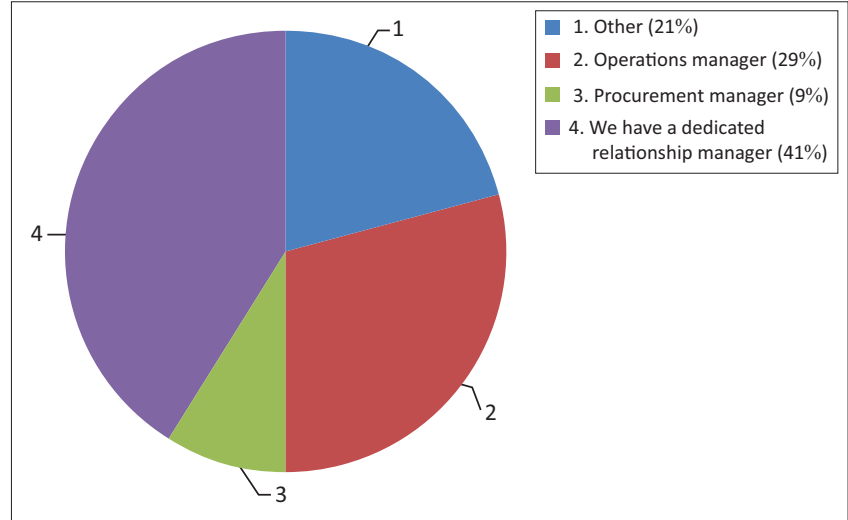

Source: Adjusted from D'Amato, Kgoedi and Swanepoel (2013:104)

FIGURE 2: Outsourcing relationship responsibility.

supply chains (Langley et al. 2009:109). This relates to the integration of any supply chain functions between channel partners and the results of that integration that can provide insight into current relational practices between LSPs and client organisations.

As depicted in Figure 2, various functional areas manage the outsourced relationship, which means that a single relationship type cannot be applied across the board. This could pose a challenge for the LSP in terms of trying to standardise its approach across multiple clients. Results of the survey show that $41.2 \%$ of respondents indicated that a dedicated relationship manager oversees the relationship with the outsourced partner, and $29.4 \%$ indicated that the operations manager oversees the relationship. The responses given under 'other' include planning and logistics manager, supply chain business unit, various managers, managing directors, distribution and warehouse manager, commercial finance, and mix of day-to-day operational interface and commercial managers on an ad hoc basis.

In terms of status of the relationship (described as 'closeness') with the outsourced partner, results showed that the majority of respondents regarded their relationship with their LSPs as close. As depicted by Figure 3, 44.1\% of respondents view the relationship as a collaborative partnership, even though each business is still seen as a separate business entity. A sizeable group (41\%) interpreted the relationship as very close - where the LSP is seen as an extension of the client's business and where joint planning and free sharing of information take place. Only $15 \%$ of respondents regarded the relationship as a mere business transaction.

The majority of respondents who described the relationship as collaborative are from the FMCG industry. This may indicate that relative to the other industries involved in the study, the FMCG industry is more progressive in terms of LSP engagement.

The researchers believe that the perception of 'closeness' could be a good indicator of the opportunity for the LSP to provide more complicated and advanced services (such as planning) to these clients. This is confirmed in a 


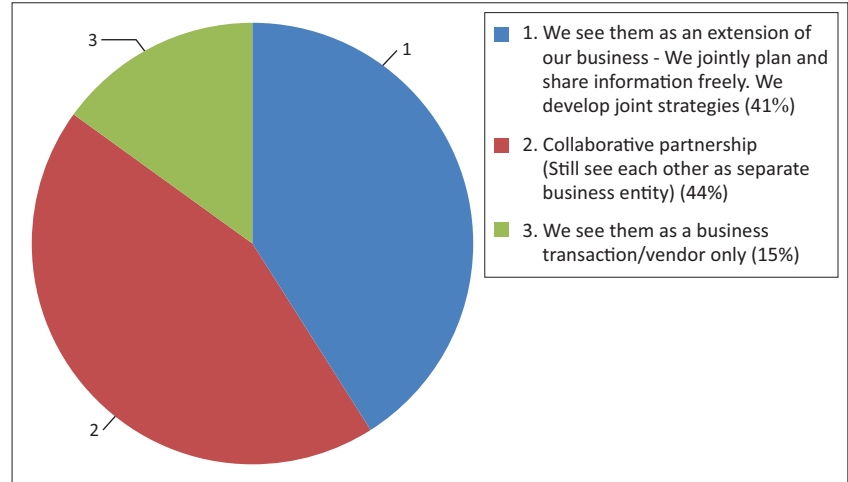

Source: Adjusted from D'Amato, Kgoedi and Swanepoel (2013:108)

FIGURE 3: Closeness of outsourcing relationship.

cross-comparison of respondents' perspectives of relationship closeness and benefits expected of converged planning and execution functions. Only those respondents who regarded their relationship with LSPs as close (an extension of their business or collaborative partnership) foresaw huge benefits from such action.

Another relational aspect tested in the survey was the responsibility for measurement of outsourced activities. A high number $(67 \%)$ of respondents indicated that planning and execution activities are measured by both the client and service provider. This shows the existence of a dual control method, which serves to ensure that performance can be justified by the LSP should there be a dispute (or vice versa). This result could also be interpreted as an unnecessary duplication of activities. A requirement for close supplier relationships is a performance management system that has the same measurement metric based on aligned strategies (Simatupang \& Sridharan 2005:259). However, it can be difficult to align measurement systems because each supply chain partner has a unique structure for revenue and costs, and required a different outcome from the supply chain relationship (Simatupang \& Sridharan 2005:259).

\section{Strategic alignment}

Strategic alignment between the LSP and the client organisation is a way of ensuring business sustainability for both organisations in the long term. To understand the strategic element of a supply chain relationship the researchers included questions relating to the existence of a supply chain strategy, as well as the linkages between the client organisation's strategy and its LSP.

A large number $(85 \%)$ of respondents indicated that their organisation had a supply chain strategy, whilst $9.1 \%$ indicated that no supply chain strategy is present in their organisation; $6.1 \%$ were uncertain if a supply chain strategy was present or not. The benefit of having a supply chain strategy is that it would most likely be aligned to the overall business strategy. Research from the literature shows that supply chains with a clear strategy tend to be more competitive and achieve better financial results than those

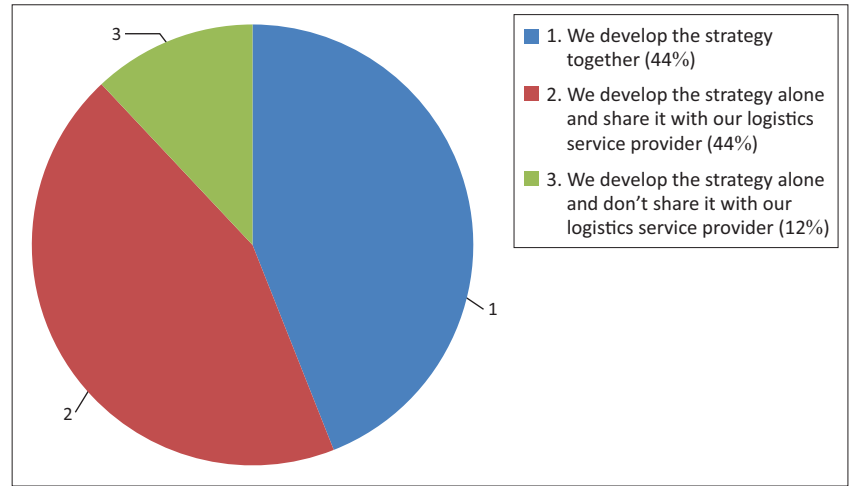

Source: Adjusted from D’Amato, Kgoedi and Swanepoel (2013:118) LSP, Logistics service providers.

FIGURE 4: Strategy development - inclusion of logistics company A.

without. The question that can be asked then is if a supply chain strategy is present in the organisation, how is the outsourced partner/s aligned to it?

As depicted in Figure 4, the research showed that 44\% of respondents develop the supply chain strategy alone and thereafter share it with the LSP. The same number of respondents develop the supply chain strategy together with outsourced partners. A relatively small number (12.1\%) develop the supply chain strategy alone and do not share it with service providers. The fact that strategic business partnerships are highly complex and multidimensional could explain why only $44 \%$ of respondents develop their strategies with inputs from their LSPs. Strategy is seen as mainly an internal function. However, LSPs are becoming more intertwined with their clients.

\section{Outsourcing practices}

To understand the way in which respondents were using logistics outsourcing as a strategy, outsourcing practices of the companies surveyed were determined by posing the following question: 'Which of the following supply chain functions do you partially or fully outsource?' A follow-up question asked for information about the involvement of LCAI in such outsourcing practices.

As shown in Figure 5, transportation (both outbound and inbound) together with warehousing management represent the most outsourced activities and LCA is already extensively involved in those functions. Figure 5 also shows that LCA is to some extent involved in all of the functions on the list through its various operating companies. These services may therefore be provided in isolation, which means there is an opportunity for LCA to consolidate complementary services such as transport planning and transport execution as single offerings.

Noteworthy is the relatively low percentage of planning functions being outsourced. This may be as a result of the importance of the function (demonstrated later in this article), and can be interpreted as a business opportunity for LCA and other LSPs. 


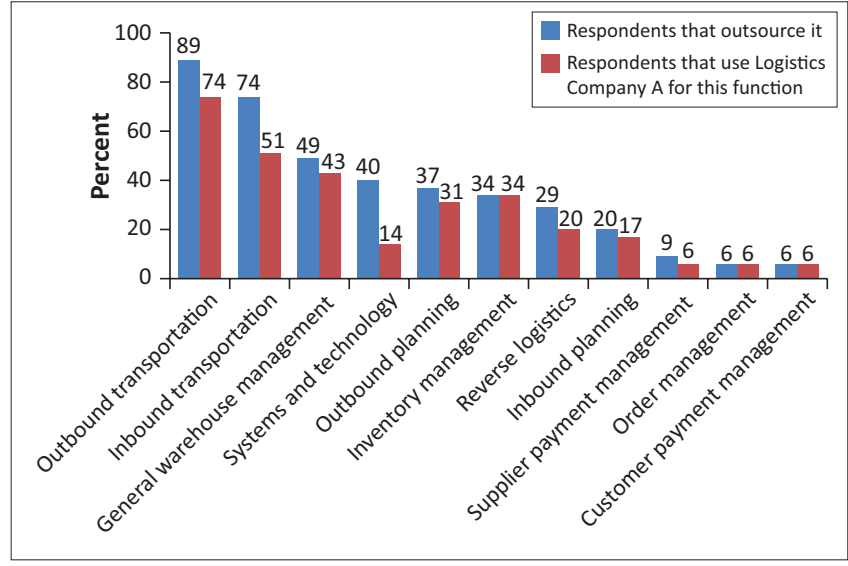

Source: Adjusted from D'Amato, Kgoedi and Swanepoel (2013:123) LCA, logistics company A.

FIGURE 5: Logistics functions outsourced by respondents and the involvement of logistics company A.

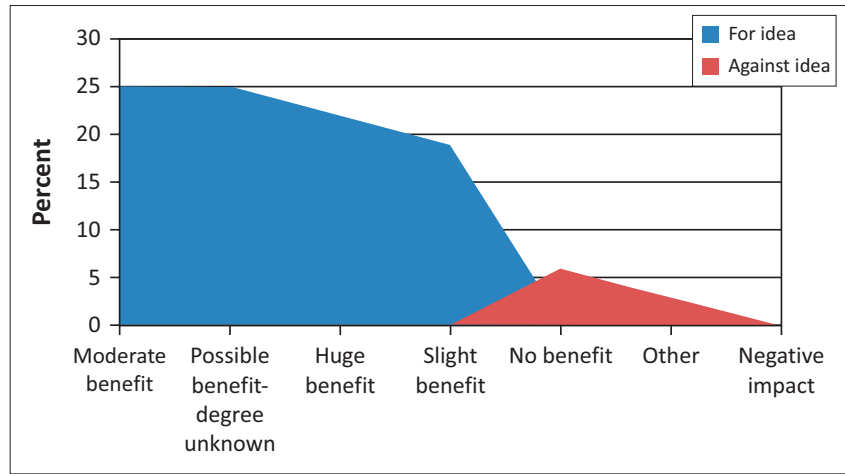

Source: Adjusted from D’Amato, Kgoedi and Swanepoel (2013:134) LSP, Logistics service providers.

FIGURE 6: Attitude towards LSP providing both planning and execution functions.

\section{Potential value of convergence of planning and execution functions}

One of the main aims of the study was to determine the value at stake for a client of an LSP providing both planning and execution as a combined service. The exact details of how this service would be structured would be dependent on the individual client requirements as well as the structure of the LSP. For example, LCA offers a variety of services under its brand, but these might be performed by different companies within the group.

The majority of respondents see some benefit in their LSP providing both planning and execution activities (as depicted in Figure 6). The sum of the positive responses - those indicating 'I foresee a huge benefit', 'I foresee a moderate benefit', 'I foresee a slight benefit', 'There is a possible benefit although I don't know to what degree yet', adds up to $91 \%$ of all responses. Only $6 \%$ of respondents demonstrated that they did not foresee any benefits, whilst no respondents thought that convergence of planning and execution would have a negative impact on their business.

For respondents that answered positively regarding whether they foresaw benefits in the convergence of planning and execution activities with LSPs, there was also a follow-up

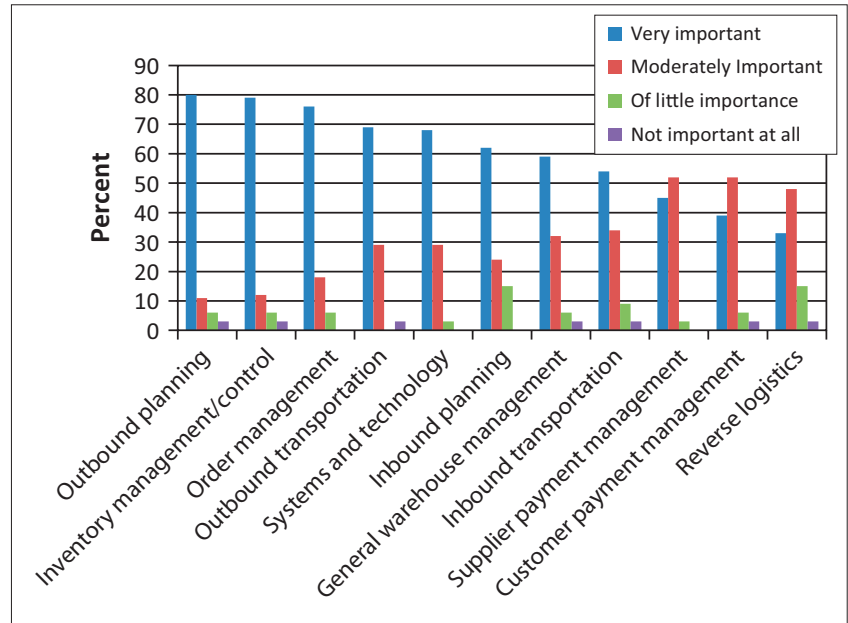

FIGURE 7: Importance of logistics functions to business success.

open-ended question asking them to elaborate on what these benefits would be. Cost saving is a benefit that was mentioned directly more than once here. Other foreseen benefits identified focused indirectly on business efficiency and effectiveness (risk management, better utilisation of expertise, business simplification, outbound transportation improvement, better decision making, continuous improvement of customer service levels, and avoidance of finger pointing).

Respondents who saw a moderate benefit in the convergence of planning and execution also mentioned efficiency gains (better skill utilisation, better utilisation of fleet). Interestingly, these respondents also mentioned benefits directly and indirectly related to improved planning (better operational scheduling, improved visibility, better alignment between supply chain partners, and improved customer service levels). Respondents who only foresaw a slight benefit of the convergence of planning and execution gave few explanations of potential benefits but did mention the possibility of collaborative planning and improved planning throughout Africa.

To further contextualise the opinion of respondents on the potential value of convergence of the planning and execution functions, one should consider the relative importance that respondents attached to various logistics activities. Figure 7 shows the responses that were received when respondents were asked which logistics functions are considered important for business success. From Figure 7 it can be concluded that the top three functions that respondents regarded as very important for business success are outbound planning, inventory management and/or control, and order management.

The emphasis is therefore mainly on outbound logistics activities, assuming that inventory management can also form part of the outbound function. It is interesting that outbound planning is considered the most important activity. It is also one of the activities which are mostly managed as an in-house function. One conclusion that can be made from this result is that it will take a considerable 
effort from an LSP to convince a potential client (or existing one for which other functions are managed) to outsource outbound planning. The client will have to be very certain of the LSP'S ability to consistently provide high-quality service levels in this regard and should be convinced of the potential benefits.

Respondents who see a moderate benefit utilise tools of a less formal nature. Systems are included in the tools; however, communication and meetings are introduced with these respondents. Communication is an imperative link in the integration between supply chain partners. Meetings assist in identifying opportunities and threats specific to the environment in which the supply chain partners operate.

\section{Conclusion}

Converging planning and execution through one LSP provides various potential benefits. The survey results show that the main benefit is cost-efficiency; however, secondary benefits that relate to business efficiencies, such as better planning and business simplification, were also foreseen by respondents.

Planning is seen by respondent organisations as a very important function, and for that reason it is mostly performed in-house. When LCA (or any other LSP) approaches a client with the intent to secure convergence of planning and execution activities, it must communicate what the potential benefit of such a strategy would be. Although businesses primarily exist to provide shareholder value, it is recommended that focus is not placed exclusively on cost, but also on business simplification (elimination of duplicate activities such as planning) and holistic benefits to the supply chain.

Planning and execution comprise an essential part of any logistics activity, integrating various functions into a central structure, whether this is done within a company, between two companies or fully outsourced to an LSP. The more planning and overseeing of supply chain activities that can be done from a central point, the better the integration of these activities. It was highly apparent from the study that there are benefits to the client organisation to do this, but there are also benefits to the LSP in terms of being able to combine resources to do planning and execution for multiple clients within the same structure. This is the case even if the clients are not aware or indifferent to the fact that a company such as LCA might be consolidating many daily requests from many clients into a centralised planning department that can then interpret and plan the best and most cost-effective way to execute those functions.

LSPs could potentially develop cost models that charge a premium rate to clients for their providing the planning combined with the execution function. This would need to be cheaper than the cost that the client would have paid for both activities separately, but the LSP could potentially still be making more profit due to the lower internal costs that come from centralising this function across many logistics activities or clients.

Ultimately, strategic partnering organisations need to be aligned in terms of their strategy, relationships, service requirements and offerings. Organisations that strive to attain a distinct competitive advantage have recognised collaborative planning with supply chain partners as key to successful initiatives for fulfilling customer needs. These organisations enter into strategic relationships with supply chain partners and jointly collaborate and plan to develop strategies that deliver world-class execution of outsourced functions.

For effective execution supply chain partners must plan and agree on performance measures. Performance measurement will link execution of the outsourced function with the collaborative plans. It will assess and provide results on the effectiveness of collaborative planning. Performance measurement can therefore be used to improve collaborative planning on an ongoing basis. Integrated planning and execution have a positive significant impact on business activities and result in the reduction of duplication of various activities.

The survey feedback indicated a high response of organisations agreeing that they foresee benefits in the outsourced partner providing both planning and execution. This implies that organisations are realising that there can be benefits from integrating planning and execution. Benefits such as improved performance visibility, better operational efficiency, and elimination of duplicate activities can be experienced. Convergence of planning and execution can also lead to improved strategic collaboration with the outsourced partner.

\section{Acknowledgements Competing interests}

The authors declare that they have no financial or personal relationships which may have inappropriately influenced them in writing this article.

\section{Authors' contributions}

A.A.D. (University of Johannesburg) and P.J.K. (University of Johannesburg) wrote the article from the findings of the M.Com. Business Management dissertation conducted by students A.A.D., S.K. (University of Johannesburg) and G.S. (University of Johannesburg). J.W. (University of Johannesburg), A.D. (University of Johannesburg) and P.K. acted as supervisors of the dissertation.

\section{References}

Bask, A., 2001, 'Relationships among TPL providers and members of supply chains: A strategic perspective', The Journal of Business and Industrial Marketing 16(6), 470-486. http://dx.doi.org/10.1108/EUM0000000006021

Council of Supply Chain Management Professionals, 2012, 'CSCMP supply chain management', viewed 25 July 2012, from http://cscmp.org/aboutcscmp/ definitions.asp 
Cranfield University, 2010, 'Supply Chain strategy in the boardroom: Interim findings', viewed 28 June 2012, from http://www.solvingefeso.com/upload/Supply_chain_ viewed 28 June 2012, from http://WwW.Solvingefe

D’Amato, A.A., Kgoedi, S. \& Swanepoel, G., 2013, 'Convergence of logistics planning, execution and measurement on outsourcing', Minor dissertation based on a multidisciplinary research project, submitted in partial fulfilment of the requirement for the degree Magister Commercii, University of Johannesburg.

Creswell, J., 1994, Research design: Qualitative and quantitative approaches, Sage, London.

Fabbe-Costes, N., Jahre, M. \& Roussat, C., 2009, 'Supply chain integration: The role of logistics service providers', International Journal of Productivity and Performance Management 58(1), 71-91. http://dx.doi.org/10.1108/17410400910921092

Knemeyer, M.A. \& Murphy, P.R. 2005, 'Exploring the potential impact of relationship characteristics and customer attributes on the outcomes of third-party logistics arrangements', Transportation Journal 44(1), 5-19.

Langley, C.J. jun., Coyle, J.J., Gibson, B.J., Novack, R.A. \& Bardi, E.J., 2009, Managing supply chains: A logistics approach, 8th edn., South-Western, Chula Vista.

Langley, C.J. jun. \& Capgemini Consulting, 2011, 16th Annual Third Party Logistics Study, viewed 26 August 2014, from http://www.3plstudy.com/downloads/ previous-studies
Large, R.O., Kramer, N. \& Hartmann, R.K., 2011, 'Customer-specific adaptation by providers and their perception of 3PL-relationship success', The International Journal of Physical Distribution \& Logistics Management 41(9), 822-838. http:// Journal of Physical Distribution \& Logistics
dx.org/10.1108/09600031111175807

Lukassen, P.J.H. \& Wallenburg, C.M., 2010, 'Pricing third-party logistics services: Integrating insights from the logistics and industrial services literature', Transportation Journal 49(2), 24-43.

Rahman, S., 2011, 'An exploratory study of outsourcing 3PL services: An Australian perspective'. Benchmarking: An International Journal 18(3), 342-358.

Simatupang, T.M. \& Sridharan, R., 2005, 'An integrative framework for supply chain collaboration', The International Journal of Logistics Management 16(2), 257-274. http://dx.doi.org/10.1108/09574090510634548

Tan, P., 2000, 'Business excellence in entrepreneurship through motivation audit', Managerial Auditing Journal 15(7), 338-347. http://dx.doi. org $/ 10.1108 / 02686900010344610$

Wilding, D., Waller, A., Rossi, S., Geldard, C., Mayhew, S., Cigolini, R. \& Metcalfe, C., 2010, Supply chain strategy in the board room, Cranfield University Working Paper, viewed 13 January 2013, from http://dspace.lib.cranfield.ac.uk/handle/1826/5272

Zigmund, W.G. \& Babin, B.J., 2007, Essentials of marketing research, Thompson South-Western, Boston, MA. 